\title{
Tissue Doppler Derived Biphasic Velocities During the Pre and Post-Ejection Phases: Patterns, Concordance and Hemodynamic Significance in Health and Disease
}

\author{
Alaa Mabrouk Salem Omar ( $\square$ alaamomar2016@gmail.com ) \\ Mount Sinai Morningside Hospital https://orcid.org/0000-0002-5184-9421 \\ Diana Maria Ronderos Botero \\ BronxCare Health System \\ Javier Arreaza Caraballo \\ Mount Sinai Morningside Hospital \\ GaHee Kim \\ Mount Sinai Morningside Hospital \\ Yeraz Khachatoorian \\ Mount Sinai Morningside Hospital \\ Jaclyn Kliewer \\ Mount Sinai Morningside Hospital \\ Mohamed Ahmed Abdel Rahman \\ Mount Sinai Morningside Hospital \\ Osama Rifaie \\ Mount Sinai Morningside Hospital \\ Jonathan N Bella \\ BronxCare Health System \\ Edgar Argulian \\ Mount Sinai Morningside Hospital \\ Johanna Contreras \\ BronxCare Health System
}

\section{Research Article}

Keywords: heart failure, tissue Doppler imaging, pre-ejection, post-ejection

Posted Date: January 7th, 2022

DOI: https://doi.org/10.21203/rs.3.rs-1222157/v1 
License: (c) (i) This work is licensed under a Creative Commons Attribution 4.0 International License. Read Full License 


\section{Abstract \\ Background}

Pre-(PRE) and post-ejection (POE) velocities by mitral annular tissue Doppler (TD) are biphasic and may be related to myocardial deformations. We investigated the predominance and concordance of TD-PRE and POE velocities and their effect on myocardial functions in controls and in HF patients.

\section{Methods}

Retrospectively, $84 \mathrm{HF}$ patients [57.6 years, $28(33 \%)$ females, NYHA: $2.3 \pm 0.6$, EF: $55 \pm 15 \%, 52(62 \%)$ preserved $\mathrm{EF}$, and $32(38 \%)$ reduced $\mathrm{EF}], 42$ normal young controls, and 26 asymptomatic age matched controls were included. Echocardiography was done and from mitral annular tissue Doppler recordings, the biphasic PRE and POE velocity signals were identified and compared between groups.

\section{Results}

While controls had almost always predominantly positive PRE and negative POE, HF had more negative PRE and positive POE. Moreover, almost all controls exhibited normal concordance (positive PRE and negative POE). HF exhibited more abnormal concordance which was significantly associated with worse NYHA, and parameters of diastolic and systolic functions. Opposite PRE and POE velocities correlated significantly in all groups (PREp vs POEn: young: $r=0.52, p<0.001$, age controls: $r=0.79, p<0.001$, HFpEF: $r=0.56, p<0.001$, HFrEF: $r=0.42, p=0.018$; PREn vs POEp: young: $r=0.25, p=0.1$, age controls: $r=0.42, p=0.04$, HFpEF: $r=0.43, p=0.004$, HFrEF: $r=0.61, p<0.001$ ) and the ratios PRE-P/N and POE-N/P correlated significantly with $E / e^{\prime}$ in HF only.

\section{Conclusions}

In physiological state, TD signals are predominantly positive during PRE and negative during POE. Opposite PRE and POE velocities corelate, representing the PRE-generation and POE-reversal of shortening-stretch relationships, the attenuation of which in HF may be related to elevated LV filling pressures. In HF, partially or completely reversed concordance of PRE and POE is associated with progressive worsening of clinical and hemodynamic profiles.

\section{Background}

Heart failure (HF) is a leading cause of death worldwide, the incidence and the prevalence of which is only expected to increase especially in the face of an aging population ${ }^{1}$. Several classifications for heart failure exist, the most acceptable of which is based on left ventricular (LV) ejection fraction (EF) into HF with preserved EF (HFpEF) and reduced EF (HFrEF), and based on functions into systolic HF and diastolic 
$\mathrm{HF}^{2}$. Regardless of the type of classification, current models fail to encompass the mechanistic behaviors of myocardial structure and function in health and disease. For instance, despite the intuitive separation between systole and diastole as two consecutive phases of the cardiac cycle, it is impossible to separate them functionally. Surprisingly, large lack of understanding exists for the pre-ejection and post-ejection phases despite that these brief periods of the cardiac cycle are crucial for pressure buildup and loss that are essential for systolic ejection and diastolic filling, respectively.

Velocities during pre-ejection (PRE) and post-ejection (POE) recorded by tissue Doppler imaging (TDI) of the mitral annulus are biphasic. Several studies have shown that the positive velocity during PRE (PREp) represents a less load independent state of myocardial contractility and is associated with clinical and hemodynamic variables in patients with systolic dysfunction ${ }^{3,4}$. Moreover, we have recently reported that PREp is associated with LV filling pressure in systolic dysfunction ${ }^{5}$ and in patients with mitral regurgitation ${ }^{6}$. The biphasic nature of these velocities is, reportedly, related to myocardial deformation in the form of endocardial shortening and epicardial stretch in the PRE and their reversal during the $\mathrm{POE}^{7}$. These velocities and their expression in health and disease and their relationship to clinical and hemodynamic profiles in HF patients have not been well studied. In the current study, we have aimed to investigate the normal predominance of the biphasic velocities during PRE and POE phases and the PREPOE biphasic velocity concordance in normal controls and in patients with heart failure and the effects of different concordance variations on myocardial functions in patients with HF.

\section{Methods}

In a retrospective study protocol, patients referred to the echocardiography laboratory with symptoms suggestive of heart failure were included. In addition, normal young controls (age $<40$ years) and patients referred for routine echocardiographic examination who had no symptoms or structural myocardial abnormalities and who were age matched to heart failure patients were also included in the study (young controls and age matched controls, respectively). Patients were excluded if they had terminal illness, were in atrial fibrillation, had more than mild valvular disease, or had less than acceptable echocardiographic image quality. Demographic, clinical and laboratory variables were compared between groups and, in addition, conventional echocardiographic examination focused on tissue Doppler recording and measurements were also compared between subgroups.

\section{Echocardiographic examinations:}

All echocardiographic studies were performed with a commercially available echocardiography systems equipped with a 2.5-MHz phased array transducer. Digital routine grayscale 2-dimensional and tissue Doppler cine loops from 3 consecutive beats were obtained at end-expiratory apnea from standard apical views at depths of $12-20 \mathrm{~cm}$. Sector width was optimized to allow for complete myocardial visualization while maximizing the frame rate. Gain settings were adjusted for routine clinical grayscale 2D imaging to optimize endocardial definitions. LV-EF was calculated from the apical 2- and 4-chamber images using the biplane Simpson's technique. All measurements were made in $\geq 3$ consecutive cardiac cycles and 
average values were used for the final analyses. The pulsed-wave Doppler-derived transmitral velocity and spectral tissue Doppler-derived mitral annular velocity were obtained from the apical 4-chamber view. The early diastolic wave velocity $(E)$ and the late diastolic atrial contraction wave velocity $(A)$, were measured using pulsed-wave Doppler recording, and the early diastolic mitral annular velocity ( $\left.\mathrm{e}^{\prime}\right)$ and systolic velocity $\left(s^{\prime}\right)$ were measured and averaged from the septal and lateral mitral annular positions. The E/e' ratio was calculated to assess LV filling pressure (LVFP) for all patients.

\section{Pre and post-ejection tissue velocities: patterns, predominance and concordance}

From the mitral annular tissue Doppler recordings, the biphasic pre-ejection (PRE) and post-ejection (POE) velocity signals were identified (figure 1). PRE was identified as a positive signal (PREp) followed by a negative signal (PREn) that preceded the ejection systolic velocity (s'). POE was identified as a negative signal (POEn) followed by a positive signal (POEp) that was positioned between the ejection systolic velocity ( $\left.s^{\prime}\right)$ and early diastolic velocity ( $\left.e^{\prime}\right)$. All positive and negative signals of both phases were measured and averaged from the septal and lateral mitral annular positions. The ratio of both PRE and POE velocities were obtained as chronologically occurring during the cardiac cycle as the former divided by the later in the form of the positive to negative PRE (PRE-P/N), and negative to positive POE (POE$N / P)$. The predominance of the biphasic PRE was defined as positive if $P R E-P / N$ was $>1$, and negative if PRE-P/N was $\leq 1$. The predominance of the biphasic POE was defined as negative if POE-N/P was $>1$, and positive if IR-N/P was $\leq 1$. Next, the concordance of both biphasic velocities was defined as Normal if PRE was predominantly positive and POE was predominantly negative, reversed PRE, if both velocities were predominantly negative, reversed POE if both velocities were predominantly positive, and complete reversal if PRE was predominantly negative and POE was predominantly positive.

\section{Statistical methods:}

Categorical data are presented as number (\%), and were compared using chi square test. Continuous data are presented as mean $\pm S D$. Data were tested for normality using Kolmogorov-Smirnov and Shapiro-Wilk tests and, accordingly, continuous data were compared using t-test or analysis of variance (ANOVA) if they are normally distributed or the Mann-Whitney $U$ test if they are not normally distributed. The correlations between different variables were done using the Pearson correlation coefficient. Cut of values for prediction of E/e' $>13$ were tested using receiver-operator-characteristic (ROC) curves. Reproducibly analysis were done using interclass correlation coefficient and absolute differences for inter-observer and intra-observer differences of repeated measures in 15 randomly selected patients. Differences were considered statistically significant at $p<0.05$. All analyses will be performed with a commercially available software (SPSS, version 23.0; SPSS, Inc).

\section{Results}

The initial study group included 102 patients. 18(18\%) patients were excluded due to atrial fibrillation in $5(5 \%)$ patients, and significant mitral valve disease in $13(13 \%)$ patients [6 patients with significant rheumatic mitral stenosis, and 7 patients with moderate to severe mitral regurgitation due to leaflet 
tethering], Accordingly, the final study cohort consisted of 84 heart failure patients [age: $57.6 \pm 8$ years, 28(33\%) females, NYHA: $2.3 \pm 0.6$, EF: $55 \pm 15 \%]$. Of these, 52(62\%) patients had HFpEF (EF: $65 \pm 5 \%$ ), and $32(38 \%)$ patients had HFrEF (EF: $39 \pm 9 \%)$. In addition, 42 young normal subjects [age: $27 \pm 4$ years, $5(12 \%)$ females, EF: $66 \pm 5 \%$ ], and 26 age matched controls [age: $53 \pm 12$ years, $28(65 \%)$ females EF: $61 \pm 4.7 \%$ ] were included. Table 1 shows comparisons between all groups regarding baseline demographic clinical and echocardiographic variables. Briefly, patients with HFpEF were the oldest and had more risk factors, while patients with HFrEF had worse systolic and diastolic echocardiographic parameters.

\section{Pre and Post-Ejection phases in patients and controls:}

Table 1 summarizes comparisons between patients and controls for septal, lateral, and averaged mitral annular velocities including pre-ejection (PRE) and post-ejection (POE) variables. It was found that, patients with heart failure had lower PREp, and POEn, higher PREn and POEp, and lower ratios PRE-P/N and POE-N/P compared to controls. Among heart failure patients, HFrEF tended to have lower PREp, and POEn compared to HFpEF (PREp: $6.3 \pm 2.2$ vs. $4.3 \pm 1.6, p<0.001$; POEn: $3.3 \pm 1$ vs. $2.4 \pm 0.7$, all $p<0.001$ ) while there was no significant difference between PREn and POEp compared to HFpEF (PREn: $3.7 \pm 1.1$ vs. $3.3 \pm 1.4, p=0.225$; POEp: $3.3 \pm 1$ vs. $2.4 \pm 0.7, p=0.248$ ) and, similarly, there was no significant difference regarding both ratios (POE-P/N: $1.8 \pm 0.7$ vs. $1.5 \pm 1.03, p=0.282 ; P O E-N / P: 1.3 \pm 0.5$ vs. $1.1 \pm 1.04, p=0.203$ ). On the other hand, with the exception of a higher POEp in the normal subjects, none of the PRE or POE velocities were different between normal subjects and matched controls. Moreover, it was noted that normal and age matched controls had almost always a predominantly positive PRE and predominantly negative POE, while predominantly negative PRE and predominantly positive POE occurred almost always in HF patients (Figure 2)

\section{Concordance between biphasic velocities of pre and post-ejection phases in patients and controls:}

Next, all patients and controls were compared based on our definition of concordance between both biphasic velocities (Normal: PRE predominantly positive and POE predominantly negative, reversed PRE: both PRE and POE predominantly negative, reversed POE: both PRE and POE predominantly positive, and complete reversal: PRE predominantly negative and POE predominantly positive, Figure 2). It was found that almost all normal subjects and matched controls exhibited normal concordance [normal subjects: 39 (93\%) subjects, and matched controls: $23(96 \%)$ patients], while in normal subjects, $3(7 \%)$ subjects exhibited abnormal concordance (reversed PRE in 1 reversed POE in 1, and total reversion in 1), and in matched controls one (4\%) patient exhibited reversed POE.

Importantly, abnormal concordance was found in significantly more HF patients compared to controls [49(58\%) patients vs. 4(6\%) controls, $p<0.001$ ]. Abnormal concordance occurred in $24(46 \%) \mathrm{HFpEF}$ patients and $25(67 \%) \mathrm{HFrEF}$ patients, $(\mathrm{p}=0.003)$. All types of concordance were observed in patients with $\mathrm{HFpEF}$, however, in patients with HFpEF, almost all patients had abnormal concordance [12(44\%) reversed POE, and $13(48 \%)$ totally reversed concordance]. Importantly, concordance seemed to be significantly associated with NYHA functional class such that the best NYHA was in normal concordance (1.6 \pm 1$)$ and the worst was in reversed concordance $(2.6 \pm 0.5)$, while reversed PRE and POE was in between normal 
and reversed ( $2 \pm 1.2$ and $2.3 \pm 0.6$, respectively). Similar patterns were observed in parameters of diastolic and systolic functions where the highest E/A and E/e', the lowest average $e^{\prime}$, the largest ESV and EDV and the lowest EF were noted in reversed concordance, while all these parameters were noted to be best in normal concordance and were intermediate between both groups in reversed PRE and POE. Importantly, in heart failure patients, bundle branch block was not significantly different between groups, while intraventricular conduction delay was most frequent in patients with totally reversed concordance (table 2). Moreover, electrocardiographic QRS duration was lowest in patients with normal concordance, larger in patients with reversed concordance among which it was largest in patients with totally reversed concordance (table 2).

\section{Correlations for biphasic pre and post-ejection waves:}

As suggested by the concordance of the biphasic waves, the main waves in the normal pattern were the positively directed in PRE and negatively directed in POE. Correlations noted in our study between different PRE and POE velocities are summarized in table 3 and Figure 3. When correlation was checked between PREp and POEn it was found that both waves correlated significantly in all study subgroups, while the correlations were stronger in normal and matched controls $(0.52,0.79$, respectively, all $p<0.001)$ and HFpEF $(r=0.56, p<0.001)$, it was slightly weaker in patients with HFrEF $(r=0.42, p=0.018)$. On the other hand, correlations between PREn and POEp were mainly noted in heart failure patients as no correlation was noted in normal subjects $(r=0.25, p=0.107)$, and only a weak correlation was noted in matched controls $(r=0.42, p=0.042)$. The correlation became slightly stronger in $\operatorname{HFpEF}(0.43, p=0.005)$ and was strongest in HFrEF $(r=0.611, p<0.001)$. As such it was noted that the pattern of correlation was opposite in controls and heart failure between signals associated with normal concordance and signals associated with reversed concordance showing the normal concordance signals correlate better in controls and reversed concordance signals correlate better in HF patients.

Correlation between the ratios PRE-P/N and POE-N/P, however, showed significant strong correlations in normal young subjects, weaker correlations in matched controls and HFpEF, while it was the strongest in HFrEF.

\section{Correlations of the pre and postejection waves versus E/e':}

Correlations noted in our study against left ventricular filling pressures as expressed by E/e' are summarized in table 3 and Figure 3. Importantly, it was shown that, most of the correlations of the biphasic velocities were noted in HF patients and not in controls. Briefly negative correlations were found between E/e' and PREp in patients with HFpEF and HFrEF ( $r=-0.51,-0.4, p<0.001,=0.025)$, between $E / e^{\prime}$ and POEn in patients with HFpEF only $(r=-0.43, p=0.002)$, between $E / e^{\prime}$ and POEp in patients HFrEF only $(r=-0.36, p=0.045)$, while PREn did not correlate with $E / e^{\prime}$ in any of the patients. The ratio PRE-P/N was found to correlate the strongest with $E / e^{\prime}$ in both HFpEF and HFrEF $(r=-0.55,-0.54 ; p<0.001,=0.002$, respectively), while the ratio POE-N/P showed similar however weaker pattern of correlations $(r=-0.3$, $-0.45, p=0.034,0.012$, respectively). 
Receiver operator characteristic curves (figure 4) showed that the best predictors for E/e'>13 was PRE-P/N $\leq 1.68$ (AUC:0.782, sensitivity: $86 \%$, specificity 50\%) while that for POE-N/P was $\leq 1.15$ (AUC:0.791, sensitivity: $82 \%$, specificity $64 \%$ )

\section{Reproducibility:}

Reproducibility parameters are summarized in table 4. For inter-observer variability, the absolute differences and interclass correlation coefficient for PREp were $0.03 \pm 0.93 \mathrm{~cm} / \mathrm{s}, 0.94$, respectively, for PREn were $0.72 \pm 0.67 \mathrm{~cm} / \mathrm{s}, 0.84$, respectively, for POEn were $-0.53 \pm 0.38 \mathrm{~cm} / \mathrm{s}, 0.91$, respectively, and for POEp were $0.01 \pm 0.38 \mathrm{~cm} / \mathrm{s}, 0.88$, respectively. On the other hand, for intra-observer variability, the absolute differences and interclass correlation coefficient for PREp were $0.11 \pm 0.57 \mathrm{~cm} / \mathrm{s}, 0.97$, respectively, for PREn were $-0.22 \pm 0.45 \mathrm{~cm} / \mathrm{s}, 0.93$, respectively, for POEn were $-0.17 \pm 0.31 \mathrm{~cm} / \mathrm{s}, 0.93$, respectively, and for POEp were $0.02 \pm 0.34 \mathrm{~cm} / \mathrm{s}, 0.89$, respectively.

\section{Discussion}

The main study findings are as follows: first, normally, tissue Doppler-derived biphasic signals are predominantly positive during pre-ejection (PRE) phase and predominantly negative during post-ejection (POE) phase. Second, normal concordance of both velocity signals (positive PRE and negative POE) is associated with the best clinical, hemodynamic, and functional profiles in heart failure patients. Partially reversed concordance (reversal of one of the velocity signals i.e. negative PRE and POE or positive PRE and POE) occurs in heart failure patients (both HFpEF and HFrEF) and is associated with an intermediate worsening of clinical and hemodynamic profiles. Completely reversed concordance (negative PRE and positive POE) occurs mostly in patients with HFrEF and is characterized by the worst clinical, hemodynamic, and functional profiles. Third, velocities of opposite directions during the pre-ejection and post-ejection phases exhibit positive correlations, and seem to be related to the LV filling pressures as expressed by E/e' ratio.

\section{Myocardial mechanics during the preejection and its significance}

The LV mechanical behavior during pre-ejection and post-ejection and its significance in health and disease, is a complex and controversial topic. Several studies have focused on the TDI-derived biphasic velocity during the pre-ejection period and linked it to myocardial mechanics, however, no definite explanation exists regarding the TDI waveforms during POE.

Pre-ejection is traditionally biphasic ${ }^{8}$, the first phase is referred to as electromechanical delay (EMD) and is represented by the interval from the onset of the electrocardiographic QRS complex to mitral valve closure (MVC), and the second phase is referred to as isovolumic contraction (IC) which follows MVC and is characterized by a rapid increase in LV pressure before opening of the aortic valve. Recent studies have shown that two opposing mechanical behavior occur during the pre-ejection phase: subendocardial shortening exhibited during the first phase (EMD), accompanied by stretching of the subepicardial fibers during the second phase (IC $)^{9}$. Studies have shown that this mechanical behavior can be mirrored by the 
biphasic mitral annular TDI-derived velocities ${ }^{7}$, such that the positive component occurring during the EMD corresponds to the active subendocardial shortening and the negative component occurring during the IC corresponds to the passive subepicardial stretch. The significance of this complex mechanical behavior is reportedly tightly related to efficient systolic ejection ${ }^{10}$. The predominance of the positive component of the biphasic pre-ejection velocity in our study suggests that the prevailing and dominant force of active shortening over the passive stretch functions resulting in a higher corresponding positive over negative velocity. In our study, the reversal of this predominance (negative predominance of the PRE) may suggest loss of the magnitude of the active shortening or a pathological prevalence of the stretch force associated with heart failure which may explain the worse systolic and diastolic functions.

\section{Myocardial mechanics during the post-ejection and its significance}

Reportedly, the forces produced during pre-ejection are stored in memory within the myocardial wall until the end of the ejection phase ${ }^{7,11}$. Reversal of the shortening-lengthening relationship defines the physiological onset of relaxation: it contributes to the rapid drop of the intra-ventricular pressure that occurs during isovolumic relaxation and aids in the formation of suction forces during early diastole. In our study, opposite TDI velocities of both pre-ejection and post-ejection phases correlated positively, supporting the reversal of the shortening-stretch relationships from PRE into POE.

Importantly, the positive predominance of the PRE and the negative predominance of the POE suggests that the magnitude of the active forces (shortening) during PRE and the magnitude of their release during POE exceeds that exerted by the passive fiber stretch and its reversal and further suggest that the active endocardial mechanics are the driving force in all isovolumic mechanical behavior over the passive epicardial mechanics.

\section{Concordance and its effect on myocardial mechanics and functions:}

The coupling of normal predominance of both phases, noted in our study as the normal concordance between both phases, was mostly found in normal young patients and in age matched controls. Moreover, when such normal concordance was encountered in heart failure patients, it was associated with the best clinical and hemodynamic profile. The loss of normal concordance was almost always found in heart failure patients and was characterized by either reversal of one of both phases (partial reversal) or reversal of both phases (complete reversal). The progression from normal concordance to partially reversed and finally to completely reversed concordance in our study was associated with a similar progression in severity of the clinical and hemodynamic profiles in heart failure patients. Importantly, it was uncommon to have a reversed PRE without coupled reversal of the IR, while isolated reversal of the POE was not uncommon. Partial reversal of the predominance of the biphasic velocities may be due to failure of normal transmission of the pre-ejection forces (shortening-stretch) in memory into the post-ejection phase which may lead to inappropriate diastolic behaviors (as noted in patients with HFpEF) but may also affect systolic function to a certain degree. Complete reversal, on the other 
hand, means complete disruption of the presumed PRE-POE relationships and may be due to faulty generation of PRE forces and subsequent faulty transmission of these forces into the POE.

The mechanistic explanation of these changes lies in the fact that PRE-POE relationship are based on myocardial electromechanical anisotropic coupling ${ }^{12,13}$. In normal physiological situations, the electrical activation occurs in an endocardial to epicardial direction and begins subendocardially near the apical septum and spreads rapidly toward the base. The rapid apico-basal spread of electrical activation within the subendocardium initiates the contraction sequence. The onset of subendocardial shortening coincides hemodynamically with an early rapid build-up of intraventricular pressure during the preejection period. Subepicardial deformation occurs later temporally coinciding with the onset of systolic ejection. Importantly, this apico-basal wave of endocardial shortening aids in milking blood towards the LV outflow and subsequently out of the ventricle during systole. Conversely, during repolarization, transmural electrical gradients propagate in a base-to-apex direction. As such, mechanical coupling during post-ejection (reversal of the shortening-lengthening forces) follows the same baso-apical direction aiding in formation of suction pressure and early diastolic filling.

The timing and sequence of electrical excitation in the ventricles is influenced by the impulse propagating through the His-Purkinje system and the anistropic nature of myocardium ${ }^{13}$. In patients with myocardial disease, the disruption of electrical propagation of the depolarization and repolarization wave fronts and their mechanical outcomes as a result of microscopic fibrosis or loss of gap junctions. In our study, this hypothesis may be suggested by the fact the occurrence of intraventricular conduction delay was associated with reversal of velocities especially with totally reversed concordance, and similarly, QRS duration was prolonged the most in those patients. As such this electrical disruption may lead to faulty initiation, and/or transition of mechanical forces between IC and IR and loss of mechanical coupling expressed as the shortening-lengthening forces and thus may explain the functional and hemodynamic outcomes of reversal of predominance and concordance of pre- and post-ejection velocities in our study

\section{Limitations:}

The study suffered from the following limitations: first, the sample size is small and larger studies should be conducted before the findings can be adopted to clinical practice. Second, mitral annular velocities are the result of the tethering of the fibrous structure of the mitral annulus, and as such represents only an indirect measure of myocardial mechanics. Better representation of the myocardial mechanics can be obtained using myocardial deformation imaging techniques such as speckle tracking echocardiography. Strain rate imaging would be an appropriate alternative, however, due to the lower frame rate and higher signal to noise ratio, deformations during PRE and POE can either be missed or recorded with high noise, making it less reproducible than spectral tissue Doppler of the mitral annulus. Third, mitral annular velocities represent mainly deformations in the longitudinal directions, however deformations during preand post-ejection phases occur in all other directions of contraction, namely, circumferential, radial, as well as rotational (twist). Further studies should focus and compare the relationships of deformation in other directions of myocardial contraction in PRE and POE both in health and disease. Finally, the 
relationships to systolic and diastolic functions lack invasive reference methods for comparison, further studies should consider reproduction of the correlations observed against invasively measured pressures.

\section{Conclusions}

Tissue Doppler-derived biphasic velocities during the pre- and post-ejection phases can be related to the active endocardial shortening and passive epicardial stretch forces that occur during PRE and their reversal during POE. In normal physiological state, biphasic signals are predominantly positive during PRE and predominantly negative during POE highlighting the prevalence of the active endocardial shortening over the passive epicardial stretch forces. A positive correlation between the opposite velocities of PRE and POE represent the PRE-generation and POE-reversal of shortening-stretch relationships, the attenuation of which may be related to elevated LV filling pressures in patients with heart failure as expressed by E/e' ratio. In heart failure patients, a normal concordance of both velocity signals is associated with the best clinical, hemodynamic profiles, while partially reversed (either PRE or $\mathrm{POE}$ ), and completely reversed concordance are associated with progressive worsening of clinical, hemodynamic profiles. Reversal of concordance can be explained by faulty generation and/or propagation of shortening-stretch forces due to mechanical barriers such as fibrosis or electrical abnormalities such as loss of gap junctions that occur in the myocardium of patients with heart failure.

\section{Declarations}

Ethics approval and consent to participate:

The study has been approved by the Mount Sinai Institute Review Committee (IRB), under study No.: 2101009

Consent for publication: N/A

Availability of data and materials: The datasets used and/or analysed during the current study are available from the corresponding author on reasonable request.

Competing interests: None

Funding: None

Authors' contributions

Alaa Mabrouk Salem Omar: hypothesis generation, Data Collection, Statistical Analysis, Manuscript Preparation, Publication

Diana Maria Ronderos Botero: Data Collection, Manuscript Preparation, Publication 
Javier Arreaza Caraballo: Data Collection, Manuscript Preparation.

GaHee Kim: Data Collection, Manuscript Preparation.

Yeraz Khachatoorian: Data Collection, Manuscript Preparation.

Jaclyn Kliewer: Data Collection, Manuscript Preparation.

Mohamed Ahmed Abdel Rahman: hypothesis generation, Manuscript Preparation, Publication

Osama Rifaie: hypothesis generation, Statistical Analysis, Manuscript Preparation, Publication

Jonathan N Bella, MD: hypothesis generation, Manuscript Preparation, Supervision

Edgar Argulian: hypothesis generation, Manuscript Preparation, Supervision

Johanna Contreras: hypothesis generation, Manuscript Preparation, Supervision

Acknowledgements: None

Authors' information: None

Disclosures: All authors have nothing to disclose

\section{References}

1. Mosterd A and Hoes AW. Clinical epidemiology of heart failure. Heart. 2007;93:1137-46.

2. Omar AM, Bansal M and Sengupta PP. Advances in Echocardiographic Imaging in Heart Failure With Reduced and Preserved Ejection Fraction. Circ Res. 2016;119:357-74.

3. Cho EJ, Caracciolo G, Khandheria BK, Steidley DE, Scott R, Abhayaratna WP, Chandrasekaran K and Sengupta PP. Tissue Doppler image-derived measurements during isovolumic contraction predict exercise capacity in patients with reduced left ventricular ejection fraction. JACC CardiovasC Imaging. 2010;3:1-9.

4. Lindqvist $P$, Waldenstrom $A$, Wikstrom $G$ and Kazzam $E$. Potential use of isovolumic contraction velocity in assessment of left ventricular contractility in man: A simultaneous pulsed Doppler tissue imaging and cardiac catheterization study. Eur J Echocardiogr. 2007;8:252-8.

5. Salem Omar AM, Tanaka H, Matsumoto K, Tatsumi K, Miyoshi T, Hiraishi M, Tsuji T, Kaneko A, Ryo K, Fukuda Y, Kawai $\mathrm{H}$ and Hirata K. Tissue Doppler imaging-derived myocardial acceleration during isovolumetric contraction predicts pulmonary capillary wedge pressure in patients with reduced ejection fraction. Circ J. 2012;76:1399-408.

6. Omar AM, Abdel-Rahman MA, Khorshid H, Helmy M, Raslan H and Rifaie O. Tissue Doppler-Derived Myocardial Acceleration during Isovolumetric Contraction Predicts Pulmonary Capillary Wedge Pressure in Patients with Significant Mitral Regurgitation. Ultrasound Med Biol. 2015;41:2108-18. 
7. Sengupta PP, Khandheria BK, Korinek J, Wang J and Belohlavek M. Biphasic tissue Doppler waveforms during isovolumic phases are associated with asynchronous deformation of subendocardial and subepicardial layers. J Appl Physiol (1985). 2005;99:1104-11.

8. Remme EW, Lyseggen E, Helle-Valle T, Opdahl A, Pettersen E, Vartdal T, Ragnarsson A, Ljosland M, Ihlen $\mathrm{H}$, Edvardsen $\mathrm{T}$ and Smiseth OA. Mechanisms of preejection and postejection velocity spikes in left ventricular myocardium: interaction between wall deformation and valve events. Circulation. 2008;118:373-80.

9. Sengupta PP. Exploring left ventricular isovolumic shortening and stretch mechanics: "The heart has its reasons...". JACC Cardiovasc Imaging. 2009;2:212-5.

10. Campbell KB and Chandra M. Functions of stretch activation in heart muscle. J Gen Physiol. 2006;127:89-94.

11. Sengupta PP, Khandheria BK, Korinek J, Wang J, Jahangir A, Seward JB and Belohlavek M. Apex-tobase dispersion in regional timing of left ventricular shortening and lengthening. J Am Coll Cardiol. 2006;47:163-72.

12. Durrer D, van Dam RT, Freud GE, Janse MJ, Meijler FL and Arzbaecher RC. Total excitation of the isolated human heart. Circulation. 1970;41:899-912.

13. Sengupta PP, Tondato F, Khandheria BK, Belohlavek M and Jahangir A. Electromechanical activation sequence in normal heart. Heart Fail Clin. 2008;4:303-14.

\section{Tables}

Table 1: Baseline demographic, clinical and echocardiographic characteristics in heart failure patients as well as normal and age matched controls 


\begin{tabular}{|c|c|c|c|c|c|}
\hline & $\begin{array}{l}\text { HFpEF } \\
(n=52)\end{array}$ & $\begin{array}{l}\text { HFrEF } \\
(n=32)\end{array}$ & $\begin{array}{l}\text { Normal } \\
(n=42)\end{array}$ & $\begin{array}{l}\text { Age matched } \\
\text { Control } \\
(n=26)\end{array}$ & $\mathrm{p}$-value \\
\hline Age, years & $58.1 \pm 8.2$ & $56.7 \pm 8$ & $27.3 \pm 3.95$ & $53 \pm 11.474$ & $<0.001 \# \neq €$ \\
\hline Sex, (female), n(\%) & 19(37) & $9(28)$ & $5(12)$ & $17(65)$ & $<0.001$ \\
\hline Diabetic, n(\%) & $21(40)$ & $11(34)$ & $0(0)$ & $0(0)$ & 0.009 \\
\hline Hypertensive, n(\%) & $23(44)$ & $12(38)$ & $0(0)$ & $8(31)$ & $<0.001$ \\
\hline Hyperlipidemia, n(\%) & $8(15)$ & $3(9)$ & $0(0)$ & 1(4) & 0.292 \\
\hline Smoker, n(\%) & $14(27)$ & $8(25)$ & $0(0)$ & $4(15)$ & 0.037 \\
\hline $\begin{array}{l}\text { NYHA (1/2/3/4), } \\
n(\%)\end{array}$ & $4 / 31 / 15 / 0$ & $1 / 18 / 11 / 2$ & - & - & \\
\hline$E(\mathrm{~cm} / \mathrm{s})$ & $75 \pm 27$ & $88.7 \pm 21.5$ & $82.7 \pm 16.7$ & $71 \pm 18.5$ & $0.011 * \$$ \\
\hline $\mathrm{A}(\mathrm{cm} / \mathrm{s})$ & $81.8 \pm 20.7$ & $71.2 \pm 33.8$ & $56 \pm 8.1$ & $76.2 \pm 21.6$ & $<0.0019 €$ \\
\hline EDV (ml) & $99.2 \pm 21.7$ & $152.5 \pm 54.3$ & $95.4 \pm 17.8$ & $87.8 \pm 19.3$ & $<0.001 * \neq \$$ \\
\hline ESV (ml) & $35.4 \pm 10.3$ & $96.2 \pm 49.8$ & $32.2 \pm 7.7$ & $30.7 \pm 10$ & $<0.001 * \neq \$$ \\
\hline EF (\%) & $65 \pm 5.1$ & $38.9 \pm 9.2$ & $66.3 \pm 5.1$ & $61.5 \pm 4.7$ & $<0.001^{*} \neq \$ €$ \\
\hline e'-septal (cm/s) & $6.5 \pm 1.9$ & $5.6 \pm 1.7$ & $11 \pm 2.4$ & $8.6 \pm 2.3$ & $\begin{array}{l}<0.001 \# q \neq \$ \\
€\end{array}$ \\
\hline S'-Septal (cm/s) & $7.5 \pm 1.5$ & $5.6 \pm 1.8$ & $8.2 \pm 1.6$ & $8.27 \pm 1.8$ & $<0.001 * \neq \$$ \\
\hline e'-lateral (cm/s) & $8.4 \pm 2.8$ & $7.1 \pm 2.5$ & $14 \pm 2.8$ & $10.9 \pm 2.8$ & $<0.001 * \neq \$ €$ \\
\hline $\mathrm{S}^{\prime}$-lateral (cm/s) & $7.9 \pm 2$ & $6.2 \pm 1.8$ & $10.1 \pm 2$ & $8.9 \pm 1.9$ & $<0.001^{\star} \# \neq \$$ \\
\hline e'-mean (cm/s) & $7.5 \pm 2.2$ & $6.3 \pm 1.9$ & $12.5 \pm 2.5$ & $9.8 \pm 2.4$ & $\begin{array}{l}<0.001 \# q \ddagger \$ \\
€\end{array}$ \\
\hline $\mathrm{S}^{\prime}$-mean $(\mathrm{cm} / \mathrm{s})$ & $7.7 \pm 1.5$ & $5.9 \pm 1.5$ & $9.2 \pm 1.6$ & $8.5 \pm 1.6$ & $<0.001^{\star} \# \pm \$$ \\
\hline $\mathrm{E} / \mathrm{A}$ & $0.96 \pm 0.45$ & $1.41 \pm 0.77$ & $1.52 \pm 0.41$ & $0.96 \pm 0.25$ & $<0.001^{\star} \# \$ €$ \\
\hline$E / e^{\prime}$ & $10.7 \pm 4.4$ & $14.6 \pm 4.55$ & $6.63 \pm 0.83$ & $7.6 \pm 1.73$ & $<0.001^{*} \# \uparrow \neq \$$ \\
\hline $\begin{array}{l}\text { PREp (septal), } \\
\text { (cm/s) }\end{array}$ & $6.8 \pm 2.2$ & $4.5 \pm 1.9$ & $7.9 \pm 2.3$ & $7.8 \pm 2.1$ & $<0.001 * \neq \$$ \\
\hline $\begin{array}{l}\text { PREn (septal), } \\
\text { (cm/s) }\end{array}$ & $3.3 \pm 1.6$ & $3.1 \pm 1.5$ & $3 \pm 1.3$ & $3.1 \pm 1.3$ & 0.793 \\
\hline $\begin{array}{l}\text { POEn (septal), } \\
\text { (cm/s) }\end{array}$ & $3.3 \pm 1.1$ & $2.6 \pm 0.98$ & $4.5 \pm 1$ & $4.2 \pm 1.2$ & $<0.001^{\star} \# \mp \neq \$$ \\
\hline POEp (septal), & $2.6 \pm 0.8$ & $2.7 \pm 1.5$ & $1.9 \pm 0.7$ & $2.1 \pm 0.6$ & $0.002 \# \ddagger$ \\
\hline
\end{tabular}




\begin{tabular}{|c|c|c|c|c|c|}
\hline $\begin{array}{l}\text { PREp (lateral), } \\
\text { (cm/s) }\end{array}$ & $5.7 \pm 2.5$ & $4.1 \pm 1.4$ & $6.8 \pm 1.8$ & $7.5 \pm 2.4$ & $<0.001 * q \neq \$$ \\
\hline $\begin{array}{l}\text { PREn (lateral), } \\
(\mathrm{cm} / \mathrm{s})\end{array}$ & $4 \pm 1.2$ & $3.5 \pm 1.8$ & $3.2 \pm 1.4$ & $3 \pm 1.08$ & 0.0149 \\
\hline $\begin{array}{l}\text { POEn (lateral), } \\
\text { (cm/s) }\end{array}$ & $3.3 \pm 1.1$ & $2.3 \pm 0.8$ & $4.8 \pm 1.6$ & $3.5 \pm 1.1$ & $\begin{array}{l}<0.001^{\star} \# \neq \$ \\
€\end{array}$ \\
\hline $\begin{array}{l}\text { POEp (lateral), } \\
\text { (cm/s) }\end{array}$ & $2.7 \pm 0.8$ & $2.9 \pm 0.9$ & $2.1 \pm 0.7$ & $2.1 \pm 0.6$ & $<0.001 \# \uparrow \neq \$$ \\
\hline PREp (mean), (cm/s) & $6.3 \pm 2.2$ & $4.3 \pm 1.6$ & $7.1 \pm 1.7$ & $7.2 \pm 1.9$ & $<0.001 * \neq \$$ \\
\hline PREn (mean), (cm/s) & $3.7 \pm 1.1$ & $3.3 \pm 1.4$ & $3.1 \pm 0.96$ & $2.9 \pm 0.8$ & 0.0169 \\
\hline POEn (mean), (cm/s) & $3.3 \pm 1$ & $2.4 \pm 0.7$ & $3.9 \pm 1.4$ & $3.7 \pm 0.9$ & $<0.001 * \# \neq \$$ \\
\hline POEp (mean), (cm/s) & $2.6 \pm 0.7$ & $2.8 \pm 0.99$ & $2.6 \pm 1.2$ & $1.98 \pm 0.63$ & $0.0059 €$ \\
\hline $\begin{array}{l}\text { PREp/PREn (PRE- } \\
\text { P/N) }\end{array}$ & $1.8 \pm 0.7$ & $1.5 \pm 1.03$ & $2.5 \pm 1.05$ & $2.6 \pm 0.7$ & $<0.001 \# 9 \ddagger \$$ \\
\hline $\begin{array}{l}\text { POEn/POEp (POE- } \\
\text { N/P) }\end{array}$ & $1.3 \pm 0.5$ & $1.1 \pm 1.04$ & $2.2 \pm 1.07$ & $2.1 \pm 1.3$ & $<0.001 \# 9 \ddagger \$$ \\
\hline PREp-mean/S'-mean & $0.82 \pm 0.3$ & $0.7 \pm 0.2$ & $0.8 \pm 0.2$ & $0.9 \pm 0.22$ & 0.182 \\
\hline QRS duration, ms & $84.4 \pm 12.7$ & $96.2 \pm 24$ & $72.6 \pm 11$ & $79.2 \pm 18$ & $<0.001 * \neq \$$ \\
\hline
\end{tabular}

*, $\mathrm{p}<0.05$ between HFpEF and HFrEF, \#, $\mathrm{P}<0.05$ between HFpEF and normal, $\mathbf{9}, \mathrm{p}<0.05$ between HFpEF and Controls, $\neq, p<0.05$ between HFrEF and normal, $\$, p<0.05$ between HFrEF and Controls, $€, p<0.05$ between normal and controls. PREp, positive pre-ejection, PREn, negative pre-ejection, POEn, negative post-ejection, POEp, positive post-ejection. PREp, positive pre-ejection, PREn, negative pre-ejection, POEn, negative post-ejection, POEp, positive post-ejection

Table 2: Comparison of study subjects based on PRE-POE concordance 


\begin{tabular}{|c|c|c|c|c|c|}
\hline & $\begin{array}{l}\text { PREp and } \\
\text { POEn } \\
\text { (Normal, } \\
\mathrm{n}=96)\end{array}$ & $\begin{array}{l}\text { PREn and } \\
\text { POEn } \\
\text { (PRE } \\
\text { reversed, } \\
n=5 \text { ) }\end{array}$ & $\begin{array}{l}\text { PREp and } \\
\text { POEp } \\
\text { (POE } \\
\text { reversed, } \\
n=31 \text { ) }\end{array}$ & $\begin{array}{l}\text { PREn and } \\
\text { POEp } \\
\text { (Totally } \\
\text { reversed, } \\
\mathrm{n}=18 \text { ) }\end{array}$ & p-value \\
\hline Age, years & $46.7 \pm 15.4$ & $53 \pm 17.9$ & $57.4 \pm 6.92$ & $58.9 \pm 9.6$ & $<0.001 \# \uparrow$ \\
\hline Sex, (female), n(\%) & 29 & 2 & 12 & 6 & 0.671 \\
\hline $\begin{array}{l}\text { HFpEF/HFrEF/ } \\
\text { Normal/Control, n(\%) }\end{array}$ & $28 / 6 / 39 / 23$ & $4 / 0 / 1 / 0$ & $17 / 12 / 1 / 1$ & $3 / 13 / 1 / 0$ & $<0.001$ \\
\hline NYHA (I/II/III/IV), n(\%) & $3 / 24 / 6 / 1$ & $0 / 2 / 2 / 0$ & $3 / 16 / 9 / 0$ & $0 / 7 / 9 / 0$ & 0.015 \\
\hline NYHA (mean $\pm S D)$ & $1.6 \pm 1$ & $2 \pm 1.2$ & $2.2 \pm 0.6$ & $2.6 \pm 0.5$ & $0.001 \# \uparrow$ \\
\hline$E(\mathrm{~cm} / \mathrm{s})$ & $74.3 \pm 19.1$ & $95.4 \pm 25.9$ & $80.6 \pm 23.2$ & $97.5 \pm 30.7$ & 0.0019 \\
\hline $\mathrm{A}(\mathrm{cm} / \mathrm{s})$ & $71.9 \pm 22.7$ & $68.3 \pm 17.5$ & $85.8 \pm 25.1$ & $62.1 \pm 27.3$ & $0.01 \# €$ \\
\hline $\mathrm{EDV}(\mathrm{ml})$ & $98.1 \pm 24.6$ & $113.7 \pm 29.7$ & $115.7 \pm 37.57$ & $158.5 \pm 67.1$ & $<0.0019 \$ €$ \\
\hline ESV (ml) & $36.8 \pm 18.6$ & $36.4 \pm 3.5$ & $57.4 \pm 36.4$ & $98 \pm 66.7$ & $<0.0019 \$ €$ \\
\hline EF (\%) & $62.8 \pm 8.7$ & $67 \pm 4.9$ & $56.4 \pm 14$ & $44.1 \pm 14.9$ & $\begin{array}{l}<0.001 \# \uparrow \$ \\
€\end{array}$ \\
\hline e'-mean (cm/s) & $9.8 \pm 3.1$ & $8.5 \pm 4.1$ & $7 \pm 1.9$ & $6 \pm 1.9$ & $<0.001 \# 9$ \\
\hline $\mathrm{S}^{\prime}-$ mean $(\mathrm{cm} / \mathrm{s})$ & $8.3 \pm 1.8$ & $8.6 \pm 1.8$ & $7.3 \pm 1.9$ & $5.8 \pm 1.15$ & $<0.0019 \$$ \\
\hline$E / A$ & $1.1 \pm 0.4$ & $1.53 \pm 0.73$ & $0.98 \pm 0.4$ & $1.7 \pm 0.87$ & $<0.0019 €$ \\
\hline$E / e^{\prime}$ & $7.9 \pm 2.4$ & $12.8 \pm 5.4$ & $12.2 \pm 3.7$ & $17.1 \pm 5.3$ & $<0.001 \# q €$ \\
\hline PREp (mean), (cm/s) & $6.9 \pm 1.9$ & $4.4 \pm 0.97$ & $5.9 \pm 1.9$ & $3.3 \pm 1.1$ & $<0.001^{*} \# q €$ \\
\hline PREn (mean), (cm/s) & $3.1 \pm 0.9$ & $4.6 \pm 1.1$ & $3.7 \pm 1.3$ & $3.8 \pm 1.4$ & $<0.001 * \# 9$ \\
\hline POEn (mean), (cm/s) & $3.8 \pm 1.1$ & $3.2 \pm 0.6$ & $2.6 \pm 0.9$ & $2.2 \pm 0.6$ & $<0.001 \# 9$ \\
\hline POEp (mean), (cm/s) & $2.3 \pm 0.87$ & $1.9 \pm 0.5$ & $2.97 \pm 0.82$ & $3.3 \pm 0.9$ & $\begin{array}{l}<0.001 \# q \ddagger \$ \\
€\end{array}$ \\
\hline $\begin{array}{l}\text { PREp /PREn (PRE- } \\
\text { P/N ratio) }\end{array}$ & $2.4 \pm 0.97$ & $0.98 \pm 0.2$ & $1.64 \pm 0.56$ & $0.9 \pm 0.17$ & $<0.001^{*} \# \uparrow €$ \\
\hline $\begin{array}{l}\text { POEn/POEp (POE- } \\
\text { N/P ratio) }\end{array}$ & $2.1 \pm 1.1$ & $1.7 \pm 0.5$ & $0.87 \pm 0.19$ & $0.68 \pm 0.21$ & $<0.001 \# 9$ \\
\hline PREp-mean/S'-mean & $0.87 \pm 0.3$ & $0.5 \pm 0.1$ & $0.8 \pm 0.2$ & $0.61 \pm 0.17$ & $<0.001 * q$ \\
\hline QRS duration, ms (**) & $79.5 \pm 19.7$ & $73.6 \pm 3.1$ & $87.4 \pm 23.4$ & $98.4 \pm 23.2$ & $0.028^{\star} \#$ \\
\hline LBBB, $n(\%)(* *)$ & $2(6 \%)$ & $0(0 \%)$ & $3(10 \%)$ & $3(18 \%)$ & 0.519 \\
\hline
\end{tabular}




\begin{tabular}{|llllll|} 
RBBB, $n(\%)(* *)$ & $1(3 \%)$ & $0(0 \%)$ & $2(7 \%)$ & $0(0 \%)$ & 0.626 \\
\hline IVCD, n(\%)(**) & $0(0 \%)$ & $0(0 \%)$ & $1(3 \%)$ & $3(18 \%)$ & 0.041 \\
\hline
\end{tabular}

*, $p<0.05$ between Normal and IC reversed, \#, P<0.05 Normal and IR reversed, $9, p<0.05$ between Normal and totally reversed, $\ddagger, p<0.05$ between IC reversed and IR reversed, $\$, p<0.05$ between IC reversed and totally reversed, $€, p<0.05$ between IR reversed and totally reversed

$(\star *)$ calculated from patients with heart failure

PREp, positive pre-ejection, PREn, negative pre-ejection, POEn, negative post-ejection, POEp, positive postejection, LBBB, left bundle branch block, RBBB, right bundle branch block, IVCD, intra-ventricular consuction delay.

Table 3: Correlations observed in our study

\begin{tabular}{|c|c|c|c|c|c|c|c|c|}
\hline & \multicolumn{2}{|c|}{$\begin{array}{l}\text { HFpEF } \\
(n=52)\end{array}$} & \multicolumn{2}{|c|}{$\begin{array}{l}\text { HFrEF } \\
(n=32)\end{array}$} & \multicolumn{2}{|c|}{$\begin{array}{l}\text { Normal } \\
(n=42)\end{array}$} & \multicolumn{2}{|c|}{$\begin{array}{l}\text { Age matched } \\
\text { Control } \\
(n=26)\end{array}$} \\
\hline & $r$ & p & $\mathbf{R}$ & $\mathrm{p}$ & $\mathbf{r}$ & $\mathbf{P}$ & $\mathbf{r}$ & p \\
\hline $\begin{array}{l}\text { PREp (mean) vs. POEn } \\
\text { (mean) }\end{array}$ & 0.561 & $<0.001$ & 0.421 & 0.018 & 0.521 & $<0.001$ & 0.786 & $<0.001$ \\
\hline $\begin{array}{l}\text { PREn (mean) vs. POEp } \\
\text { (mean) }\end{array}$ & 0.425 & 0.005 & 0.611 & $<0.001$ & 0.253 & 0.107 & 0.419 & 0.042 \\
\hline $\begin{array}{l}\text { PREp/PREn (PRE-P/N) } \\
\text { vs. POEn/POEp (POE- } \\
\text { N/P) }\end{array}$ & 0.292 & 0.036 & 0.896 & $<0.001$ & 0.736 & $<0.001$ & 0.483 & 0.019 \\
\hline \multicolumn{9}{|l|}{ Versus $\mathrm{E} / \mathrm{e}^{\prime}$} \\
\hline PREp (mean), (cm/s) & 0.513 & $<0.001$ & 0.4 & 0.025 & 0.04 & 0.843 & 0.02 & 0.928 \\
\hline PREn (mean), (cm/s) & 0.07 & 0.609 & 0.144 & 0.439 & 0.177 & 0.377 & 0.06 & 0.770 \\
\hline POEn (mean), (cm/s) & 0.432 & 0.002 & 0.256 & 0.165 & 0.142 & 0.481 & 0.04 & 0.853 \\
\hline POEp (mean), (cm/s) & 0.136 & 0.342 & 0.363 & 0.045 & 0.174 & 0.385 & 0.042 & 0.844 \\
\hline $\begin{array}{l}\text { PREp/PREn (IC-P/N } \\
\text { ratio) }\end{array}$ & 0.55 & $<0.001$ & 0.54 & 0.002 & 0.20 & 0.315 & 0.06 & 0.774 \\
\hline $\begin{array}{l}\text { POEn/POEp (IR-N/P } \\
\text { ratio) }\end{array}$ & 0.3 & 0.034 & 0.45 & 0.012 & 0.225 & 0.259 & 0.05 & 0.800 \\
\hline
\end{tabular}


PREp, positive pre-ejection, PREn, negative pre-ejection, POEn, negative post-ejection, POEp, positive postejection

Table 4: Reproducibility analyses

\begin{tabular}{|llllllll|}
\hline & \multicolumn{3}{l}{ Inter-observer variability } & \multicolumn{3}{c|}{ Intra-observer variability } \\
\hline & ICC & p-value & Difference & ICC & p-value & Difference \\
\hline PREp, cm/s & 0.94 & $<0.001$ & $0.03 \pm 0.93$ & 0.97 & $<0.001$ & $0.11 \pm 0.57$ \\
\hline PREn, cm/s & 0.84 & $<0.001$ & $-0.72 \pm 0.67$ & 0.93 & $<0.001$ & $-0.22 \pm 0.45$ \\
\hline POEn, cm/s & 0.91 & $<0.001$ & $-0.53 \pm 0.38$ & 0.93 & $<0.001$ & $-0.17 \pm 0.31$ \\
\hline POEp, cm/s & 0.88 & $<0.001$ & $0.01 \pm 0.38$ & 0.89 & $<0.001$ & $0.02 \pm 0.34$ \\
\hline
\end{tabular}

PREp, positive pre-ejection, PREn, negative pre-ejection, POEn, negative post-ejection, POEp, positive postejection

\section{Figures}




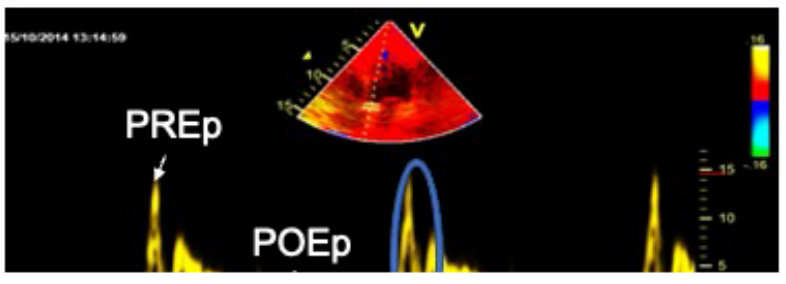

\section{PREp}



Figure 1

Biphasic myocardial velocities during pre and post-ejection phases in controls and heart failure patients. Upper panel: Tissue Doppler-derived as well schematic representation of tissue Doppler (TDI)derived mitral annular velocities in normal controls. In blue, the predominantly positive biphasic preejection (PRE), the positive component (PREp) predominates over the following negative component (PREn). In red, the predominantly negative biphasic post-ejection (POE), the negative component (POEn) 
predominates over the following positive component (POEp). Lower panel, representation of different concordance of isovolumic phases in heart failure patients, from left to right, normal concordance, predominantly positive PRE and predominantly negative POE, reversed PRE concordance, predominantly negative PRE and POE, reversed POE concordance, predominantly positive PRE and POE, totally reversed concordance, predominantly negative PRE and predominantly positive POE.

\section{Figure 2}

Frequency of predominance of biphasic tissue Doppler mitral annular velocities during pre (PRE) and postejection (POE) phases, and their concordance. Upper panel, in normal as well as age matched controls, PRE is almost always predominantly positive (PREp>PREn), while more patients with negative predominance (PREn>PREp) occurs in HFpEF and the largest number occurs in patients with HFrEF. Similarly, in normal as well as age matched controls, $\mathrm{POE}$ is almost always predominantly negative (POEn>POEp), while more patients with positive predominance (POEp>POEn) occurs in HFpEF and the largest number occurs in patients with HFrEF. Lower panel, Normal PRE-POE concordance (predominantly positive PRE and predominantly negative POE) occurs almost always in normal as well as the aged matched controls. In patients with HFpEF, lower number of normal concordance and increasing number of PRE reversed and IR reversed as well as totally reversed concordance was noted. In patients with $\mathrm{HFrEF}$, the lowest number of normal concordance, and the largest number of totally reversed concordance was observed.

\section{Figure 3}

dot plots for correlations observed in our study in subgroups. Upper panel: correlation between opposite waves of the biphasic PRE velocities (left: between positive PRE and negative POE, right: between negative PRE and positive POE). Middle panel: correlation between the ratio of positive to negative PRE waves (PRE-P/N) vs, the negative to positive POE (POE-N/P). Lower panel: correlations against E/e' as a representation of LV filling pressures (left: versus the PRE-P/N ratio, right: versus the POE-N/P ratio) 


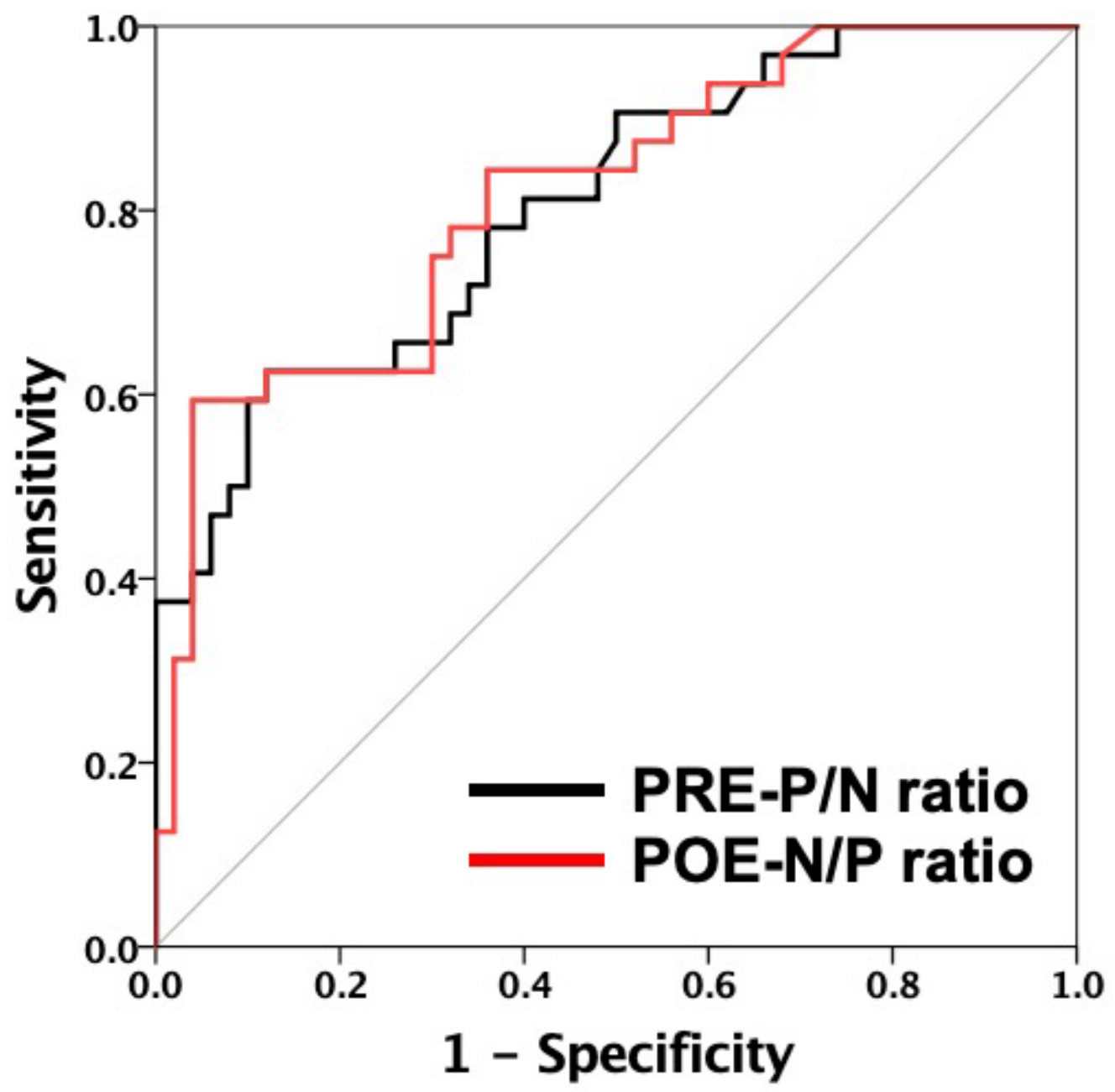

\begin{tabular}{|l|c|c|c|c|c|}
\hline & AUC & $\begin{array}{c}\text { Best } \\
\text { Predictor }\end{array}$ & P-value & $\begin{array}{c}\text { Sensitivity } \\
\%\end{array}$ & $\begin{array}{c}\text { Specificity } \\
\%\end{array}$ \\
\hline PRE-P/N ratio & 0.782 & 1.68 & $<0.001$ & 86 & 50 \\
\hline POE-N/P ratio & 0.791 & 1.15 & $<0.001$ & 82 & 64 \\
\hline
\end{tabular}

Figure 4

Receiver operator characteristic curves (ROC-curves) for best predictors of $E / e^{\prime} \geq 13$ in patients with heart failure. Black line, positive PRE and negative PRE (PRE-P/N) ratio, red line, between negative POE to positive POE (POE-N/P) ratio 